\title{
US Immigration paths for scientific researchers: Part 3
}

\author{
By Marco Pignone
}

This is the third and final part of a series in MRS Bulletin on achieving a path to a green card in the United States as it relates to scientific researchers. Following articles will focus on more specific aspects of the immigration process and go into more depth using practical examples.

$\mathrm{T}_{\mathrm{s}}^{\mathrm{o}}$ get a green card in the United States through a self-petition (not a petition by an employer), you will file a form called an I-140 petition in the EB-1 (extraordinary ability) and/or EB-2 (NIW or National Interest Waiver) categories. You will also file a green card application using Form I-485, which the US Citizenship and Immigration Services will consider only if it approves your I-140 petition. Let's look at these two categories in the US Immigration laws under which you may decide to file an I-140 petition for your green card.

\section{What is the difference between EB-1A and EB-2 (NIW)?}

Short answer: They are both "green card" categories. You can file an I-140 petition in either category or both. If you are not from China or India, you will almost always file in the NIW category only. Due to visa backlogs, if you are from China or India, you may sometimes file in the EB-1 category, the NIW category, or both.

EB-1 and EB-2 are both "green card" categories, meaning that if your petition in either of these categories is approved, you can apply for a green card through the "adjustment of status" process in the United States or through consular processing in your home country abroad. However, it is much more difficult to win your case in the EB-1 category than in the EB-2 (NIW) category. The most important thing to understand is that unless you are from China or India, there is almost never a good reason to apply in the EB-1 category. Let me explain this further.

There are limits to the number of green cards that can be issued for each country. This can cause backlogs for China and India, and the wait times have gone up and down over time for both the EB-1 and NIW categories. As the legal standard for approval in the EB-1 category

is much higher, the wait time is usually much longer in the NIW category. The wait times are published every month in the "visa bulletin," which can be found on the US Department of State's website.

If the visa bulletin indicates a " $\mathrm{C}$ " for your country, that means that a visa is "current," and you are eligible to file your green card application (I-485) immediately if you have an approved EB-1 or EB-2 petition. You could file the I-485 "simultaneously" as well, but there are reasons why that is usually not the best option. Look for future articles with case studies illustrating this issue.

\section{What qualifications do I need to file an EB-1A or EB-2 (NIW) self-petition?}

While the minimum qualifications to file are quite low, it's more important to understand what level of qualifications are required to win your case. Over time, the immigration officers who decide I-140 petitions may change their legal standards for approval, but here are some broad outlines of what you should expect. Let's look at the actual legal requirements.

\section{Factors in an EB-1A case}

The law states that you possess "extraordinary ability" if you are one of "that small percentage who have risen to the very top of the field of endeavor" when compared to everyone in your field in the entire world. You must have demonstrated "sustained national or international acclaim and that your achievements have been recognized in the field of expertise." With careful planning, it is certainly possible to win a case even if you are not actually in the top few percent in the world, but clearly the legal standard is very high.

There are two ways to win an EB-1A case and, realistically, you will only be using the second method. The first method is to win a major, internationally recognized award, such as the Nobel Prize. If you win a Nobel Prize, your immigration lawyer will be very happy and will be able to win your case with minimal effort, but otherwise, you will have to utilize the much more difficult second method.

To win an EB-1A case, you must "meet" or "win" three of the following categories:

1. Receipt of lesser nationally or internationally recognized prizes or awards for excellence in the field of endeavor.

2. Membership in associations in the field of endeavor, which require outstanding achievements of their members as judged by recognized national or international experts.

3. Published material about the foreign national and his/her work in 
professional journals, major trade publications, or major media relating to the work of the foreign national in the field.

4. Participation, either individually or on a panel, as a judge of others in the same or an allied field.

5. Original scientific, scholarly, artistic, athletic, or business-related contributions of major significance in the field of endeavor.

6. Authorship of scholarly articles in the field, published in professional or major trade publications or major media.

7. Display of the foreign national's work at artistic exhibitions or showcases. (Does not apply to scientific researchers.)

8. Performance in a leading or critical role for organizations or establishments that have a distinguished reputation.

9. Commanding a high salary/remuneration compared to others in the field.

10.Commercial success in the performing arts, as shown by box office receipts or music/video sales. (Does not apply to scientific researchers.)

In future articles, I will discuss each of these categories in-depth. In addition to winning three of the previous categories, you will have to pass a second-level analysis in which the immigration officer considers all of the evidence in support of your case in its "totality." This secondlevel analysis is required under a legal case called "Kazarian."

\section{Factors in an EB-2 (NIW) case}

I don't want you to spend too much time thinking about the wording of the law in relation to the legal standard for NIW cases. All you need to know is that the Immigration Service considers all evidence in the EB-1A categories set forth previously, and you aren't required to "meet" or "win" any categories. In other words, even a minimal amount of evidence toward a category will count in a NIW case, whereas to "win" a category in an EB-1A case requires a significant amount of evidence in three or more categories.

\section{I understand the categories, now} what are my chances of winning? You may have a number of strong positive factors in your case that can significantly improve your odds of approval. For example, a commercialized patent is a very strong positive factor. A letter from a US administrative agency such as the Department of Energy or the Department of Defense can also be a very strong positive factor. There are many possibilities, but if not, you may have to rely primarily on your citation level.

The US Immigration Service (also known as CIS) relies on Google Scholar and looks at your total number of citations. In general, CIS requires a much higher level of citations for the approval of an EB-1A case than for NIW cases. A few years ago, anyone with at least 100 citations had a good chance of winning an EB-1A case if their lawyer did a good job preparing the petition. In the last year, however, CIS has dramatically increased its standards, leading to the denial of many cases with hundreds and even thousands of citations.

As of June 2020, a good guideline to consider is filing in the EB-1A category (if you are from China or India) if you have at least 300 citations, but you should not assume that it will be granted, and you should have a backup plan to maintain your status. If you are not from China or India, you will almost never file in the EB-1A category, and to win your NIW case, you should aim for at least 75 citations.

A variety of other factors may allow you to win your case with a lower level of citations, and our law firm has won many cases with single-digit cites. However, you should do everything you can to publish and gain cites. If you only take away one concept from this article, focus on increasing your citations level.

\section{Should I file form I-485 along with my EB-1A or NIW petition?}

Form I-485 is also known as an "application to adjust status." You may also simply refer to this as a green card application. CIS will only consider this application if it approves your EB-1A or NIW "petition." This question requires a more thorough answer than I am able to provide in this article, but I will give you the short answer here, and you should look for a more in-depth discussion of this issue in future articles. Generally, you should

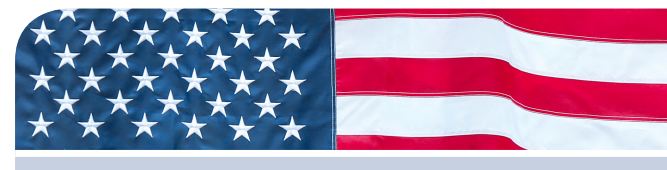

\section{How has COVID-19 affected US immigration?}

COVID-19 has had a significant impact on US immigration, but the primary effect has been the closing of US Consulates and the inability for someone abroad to obtain a visa to travel to the United States. The US Citizenship and Immigration Services has continued processing petitions and applications, and the law firm of Getson \& Schatz, P.C. has received numerous approvals of EB-1A and NIW petitions since March.

On April 22, the president announced a 60-day ban on the issuance of new "immigrant visas" (the visa category for someone who will receive a green card after they are admitted to the United States based on an approved visa petition) at US Consulates. This ban has had a minimal effect on visas thus far, as the consulates have been closed, therefore, unable to issue any visas.

Further economic turmoil and unemployment in the United States could be cause for a delay in regard to visas for employment immigration.

not file your I-485 along with your Form I-140 petition. In fact, for anyone from China or India, you have no choice and cannot legally file them together due to visa backlogs.

\section{Future articles}

I hope that this three-part overview of the immigration process has been helpful. I will begin focusing on each aspect of the process in-depth in future articles, with multiple practical examples that will begin to answer many questions.

Marco Pignone, immigration lawyer at the Philadelphia law firm Getson \& Schatz, P.C. (https://researchergreencard.com/), currently focuses on EB-1A and NIW petitions for immigrant researchers. Since 2001, he has represented immigrants in a wide range of immigration matters. 